\title{
ANTECEDENTS TO WEBSITE SATISFACTION, LOYALTY, AND WORD-OF-MOUTH
}

\author{
Brent Coker \\ University of Melbourne, St Victoria, Australia
}

\begin{abstract}
Satisfaction, loyalty, and likelihood of referral are regarded by marketers and the Big Three diagnostics leading to retail profitability. However, as yet no-one has developed a model to capture all three of these constructs in the context of the internet. Moreover, although several attempts have been made to develop models to measure quality of website experience, no-one has sought to develop an instrument short enough to be of practical use as a quick customer satisfaction feedback form. In this research we sought to fill this void by developing and psychometrically testing a parsimonious model to capture the Big Three diagnostics, brief enough to be used in a commercial environment as a modal popup feedback form.
\end{abstract}

Keywords: website quality measurement, online satisfaction, internet purchase intention

\section{INTRODUCTION}

Despite the relative maturity of E-commerce, online sales continue to grow at a phenomenal rate (U. S. Census Bureau, 2010). Recent forecasts from Forrester predict online retail sales will grow to $\$ 250$ Billion by 2014 , accounting for 8 percent of all retail sales in the US. Already, 44 percent of computers, apparel, and consumer electronics are purchased online (Forrester, 2009), highlighting the importance of the internet as a retail channel for many industries.

Since the late nineties, academics and practitioners alike have recognised the similarities between quality of experience using an e-commerce website, and quality of experience in a physical retail store. Ultimately the common function of both channels is to facilitate search, evaluation, and transaction (Teo and Yeong, 2003, Alba et al., 1997). Accordingly, well established marketing constructs known to affect the profitability of traditional channels such as customer satisfaction (Anderson and

Manuscript first received/Recebido em 01/01/2013 Manuscript accepted/Aprovado em: 01/04/2013

Address for correspondence / Endereço para correspondência

Brent Coker, Doctor of Philosophy (Electronic Commerce), Victoria University of Wellington, (2007) Bachelor of Commerce and Administration (Honours), Victoria University of Wellington, (2003) Bachelor of Commerce and Administration, Victoria University of Wellington, (2002). University of Melbourne, Department of Management \& Marketing Level 09, The Spot 198 Berkeley St. Victoria, Australia. His research focuses on explaining and predicting consumer behaviour on the internet, and identifying critical success factors contributing to the success of internet business. E-mail: bcoker@unimelb.edu.au 
Sullivan, 1993), loyalty (Dick, 1994), and likelihood of referral (Anderson, 1998) have been identified as important to evaluate the quality of website experience (e.g., Balasubramanian et al., 2003, Gruen et al., 2006, Shankar et al., 2003). The difference however is how these important variables are shaped. Issues of trust ( $\mathrm{Ba}$ and Pavlou, 2002), ease of use (Gefen et al., 2003), information content and design (Ranganathan and Ganapathy, 2002), and load speed (Ramsay et al., 1998) are all important factors affecting the quality of website experience, potentially impacting customer satisfaction.

Given the rapid growth of e-commerce and the importance of understanding customer behaviour online, several attempts have been made at developing models that measure and explain website experience quality (e.g., Loiacono et al., 2007, Yoo and Donthu, 2001, Barnes and Vidgen, 2001). However, despite these attempts, there has yet been a parsimonious model developed to explain and predict the relationships between satisfaction, loyalty, and likelihood of referral. Moreover, most models that have been developed to measure website experience quality consist of too many questions to be of practical use for deployment as a customer satisfaction survey tool. Existing models to evaluate website quality, although accurate, are typically very long, designed to capture a wide range of website quality elements not necessarily related to satisfaction, loyalty, or likelihood of referral. The WebQual scale for example consists of 36 items tapping 12 constructs to measure intentions to re-use the website (Loiacono et al., 2007). The SiteQual scale, although parsimonious with just nine items, measures intent to return but not the important antecedents shaping satisfaction, loyalty, and likelihood of referral (Yoo and Donthu, 2001).

As customer satisfaction, loyalty, and likelihood of referral are central to diagnosing service quality for Marketers, this research seeks to identify and test the key factors influencing these constructs in an online shopping environment. Moreover, the present research aims to produce a model to explain and measure these constructs that are parsimonious enough to have practical usage as a quick online satisfaction feedback form.

This study makes two main contributions. First, this study is the first to develop a single model to assess website satisfaction, loyalty, and likelihood of referral after a website experience. Second, this research is also the first to develop a short website customer satisfaction form that has practical usage in the field. Our model, while parsimonious, successfully captures the antecedents and variance of the three key variables central to diagnosing service quality for Marketers variables.

We validate our model using 168 participants engaged in an online shopping exercise, who are then instructed to complete our feedback form after a web browsing experience. The following section reviews relevant literature pertaining to the measurement of website experience quality. We then develop a set of hypotheses that define the relationships in our model. We then present the results of our model tests, followed by a discussion of the results.

\section{CONCEPTUAL FRAMEWORK AND HYPOTHESES DEVELOPMENT}

In the present research we define satisfaction as the "positive emotions consumers derive from their consumption experiences with firms" (Oliver,1999). The concept of satisfaction fits the principles of classical conditioning, whereby rewards lead to repeat behaviour. Put in the context of Marketing, when customers are rewarded 
with a satisfying purchase experience, they are encouraged to return to the same vendor next time a need to purchase the same object is evoked (Andersen \& Sullivan, 1993; Kotler, 1999). Customer satisfaction programs are sometimes clasified as a defensive marketing strategy where the focus is on customer retention. This is in contrast to offensive marketing strategies such as new product developments, advertising and line expansions where the focus is on direct recruitment (Fornell and Wernerfelt, 1987). Defensive marketing strategies are often preferable because attracting new customers through offensive marketing strategies is more expensive than retaining existing customers implementing customer satisfaction programs. Moreover, increasing customer retention rates by $5 \%$ increases profits by $25 \%$ to $95 \%$ (Reichheld and Schefter, 2000).

\section{Navigation}

Website navigation is a critical component of website experience. Based on Davies (1989) Technology Acceptance Model (TAM), consumer adoption of technology is based on perceived ease of use. In the context of online retailers, this use of technology would refer to the perceived ease at which consumers are able to explore the website and find what they are looking for (Yoo and Donthu 2001). Thus, websites with good navigation mechanisms such as functional links and a well-organized lay-out enhances overall website usage and information search (Palmer 2002).

Yoo and Donthu (2001) and Todd and Benbasat (1992) found that a positive correlation exists between customer perceptions of website navigation and satisfaction with website performance. Further support is provided by Huizingh and Hoekstra (2003) who found that navigation had a direct influence on consumer attitudinal changes towards websites.

Therefore, this study proposes that perceptions of navigation have a significant influence on satisfaction towards website experience, leading to the first hypothesis of this study

\section{Hypothesis 1: Ease of navigation is positively correlated with customer satisfaction.}

Hypothesis 2: Ease of search is positively correlated with customer satisfaction

\section{Website Performance}

Another key factor impacting consumer attitudes towards website experience is perceptions of website performance. Kim, Fiore and Lee (2007) found that consumer perceptions of online stores were negatively influenced by broken links and slow downloading speed. As technical functionality has a direct impact on other website experience attributes, such as ease of navigation, poor performance in this aspect has a detrimental impact on overall website experience amongst consumers ( Zviran, Gleezer and Avni, 2006)

In addition to technical functionality, website performance is also influenced by how attractive, i.e. aesthetically pleasing, websites are (Lii, Lim and Tseng 2004). Without tangible cues such as a physical store front and product demonstrations, website aesthetics such as a well-organized layout and animated presentations demonstrating the product in action is critical in cognitive engagement and inducing positive associations with websites (Wang, Hong and Lou, 2010). 
Therefore, it is theorized that technical performance and website aesthetics drive consumer evaluations of website performance, and consumer perceptions of website performance is an important driver of website experience satisfaction, leading to the next hypothesis of this study:

Hypothesis 3: Website Load Speed is positively correlated with customer satisfaction

Hypothesis 4: Visual Appeal is positively correlated with customer satisfaction

\section{Content}

Content is one of the most important influences on perceptions of website experience. With the absence of tangibility on the Internet, the key driver of consumer traffic online would be the subject matter available that is relevant to consumer needs or goals (Jin and Kim 2010).

In the context of e-retailers, the subject matter, or content, consumers are interested in would be information, for e,g, product and pricing information. Loiacano et al (2007) found strong evidence that a positive correlation exists between evaluations of information fit to task and tailored information with consumer intentions to re-visit and re-purchase.

In addition to relevancy, the novelty and quality of content helps to further enrich consumer experiences whilst on websites. As opposed to a website that contains plain text, a website with the right combination of animated graphics, videos and text would provide a far more enriching and valuable experience to consumers, and evidence have found higher satisfaction levels for the latter website (Wang, Hong and Lou 2010).

Moreover, intuition would suggest that consumers would be dissatisfied with websites with incomplete or incorrect information. Indeed, Liu et al (2008) found evidence to prove information quality has a positive correlation with overall customer website satisfaction. Morover, this study further proposes that novel content which is relevant and valuable to customers provides a distinct competitive advantage for eretailers.

Thus, it is theorized that the relevancy, quality and novelty of website content also drive consumer perceptions of website experience satisfaction for e-commerce websites, leading to the following hypothesis:

Hypothesis 5: Information Quality is positively correlated with customer satisfaction

Hypothesis 6: Information Relevancy is positively correlated with customer satisfaction

\section{Trust}

According to Reichheld and Schefter (2000), the most important factor consumers use to assess e-commerce websites is the level of trustworthiness conveyed. This is because with the absence of tangible attributes such as physical store locations, the ability to touch, feel and inspect the products and the risk of websites not delivering the product after receiving payment, trust is a highly important factor in providing ease of mind (Belanger, Hiller and Smith, 2002). Thus, trustworthiness is a critical riskreduction factor for online shoppers.

In the context of website experience, this study postulates consumer perceptions of trustworthiness to be an important factor which must be addressed, and in the case of e- 
commerce websites, the focus should be on perceptions of privacy and security. In today's world of sophisticated web analytics, privacy whilst browsing online is a major concern for web-users (Brown and Muchira 2004). Consumers are concerned that their details are actually being collected without their knowledge, and that information would be used for a range of purposes, from something as innocuous as pesky spam e-mails pushing various products and services, to major problems like identity theft and credit card fraud (Belanger et al 2002). Thus, it has been found that measures such as privacy statements have found to put consumers "at ease" and helped to foster feelings of trust and credibility with e-commerce websites (Kim and Benbasat 2005).

Another factor influencing perceptions of trust is how secure customers feel about conducting transactions on e-commerce websites. As opposed to traditional stores where consumers can inspect product quality to ensure expectations are fulfilled, and physical store locations where product returns can be made, a higher amount of risk exists for consumers looking to purchase online, as such tangible cues are unavailable (Jin and Kim 2010).

Therefore, customers may not feel secure entrusting their credit card or other financial details to a e-commerce website, where they are unable to examine how "secure" it would be to conduct financial transactions.

Addressing this concern, Belanger et al (2002)found that measures that help foster feelings of security such as third party security (i.e. certificates of authentication), product return guarantee, refunds, and use of reliable payment systems such as Paypal helped to increase perceptions of trustworthiness amongst online consumers. Yoo and Donthu (2001) also found evidence of how measures enhancing security help to increase perceptions of website quality.

As such, this study postulates that feelings of security and privacy helps engender perceptions of trust of Internet Retailers, resulting in the next hypothesis:

Hypothesis 7: Trust is positively correlated with customer satisfaction

\section{Satisfaction and Loyalty}

With the identification of attributes that comprise customer website experience of Internet retailer, this research shall explore the impact of said variables on the behavioral consequences of customers, and examine if a satisfying website experience can explain and predict consumer behavior towards e-retail websites in future.

It is important to note that in its emphasis on perceptions of website experience, this research is focusing on attitudes towards the website itself and not consumers intentions to conduct financial transactions, i.e. make a purchase. Consequently, in conceptualizing behavioral outcomes of a satisfying website experience, this study excludes intention to repurchase, and focuses on future behavior towards the website itself.

As such, for the purposes of this study, the outcomes of a satisfying website experience are proposed to be 1) intention of re-visit, and 2) likelihood of customer referral, which are indicators of attitudinal and behavioral loyalty.

Bansal et al (2004) found evidence proving a strong correlation exists between website performance satisfaction and website revisit intention. This helps to validate existing theoretical beliefs on how satisfied customers are more likely to engage in 
future revisits, and dissatisfied customers are more likely to leave and find alternative websites (Andersen and Srinavasan 2003).

A more recent study by Loiacano et al (2007) found further evidence proving satisfaction with website performance has a positive correlation with online customers intention to revisit.

Another important behavioral outcome of website experience would be the likelihood of customer referral. Likelihood of referral is an indicator of positive attitude, and has been proven to be a reliable indicator of future customer behavioral intention (Reicheld 2003). Indeed, prior research has found evidence supporting the link between satisfaction with website performance with likelihood of referral, where customers delighted with their previous purchase experiences have gone on to make positive product reviews online. (Liang and Cheng, 2009).

More importantly, evidence suggests 1) referrals have been proven to be a key driver of growth and profitability as in the case of Amazon and eBay (Reichheld and Schefter, 2000) and 2) consumers find referrals and customer reviews more credible and trustworthy than commercial advertising and promotions (Kotler 1999).

As such, the above discussion leads to the following two hypotheses:

Hypothesis 8: Satisfaction is positively correlated with Website Loyalty

Hypothesis 9: Satisfaction is positively correlated with Likelihood of referral

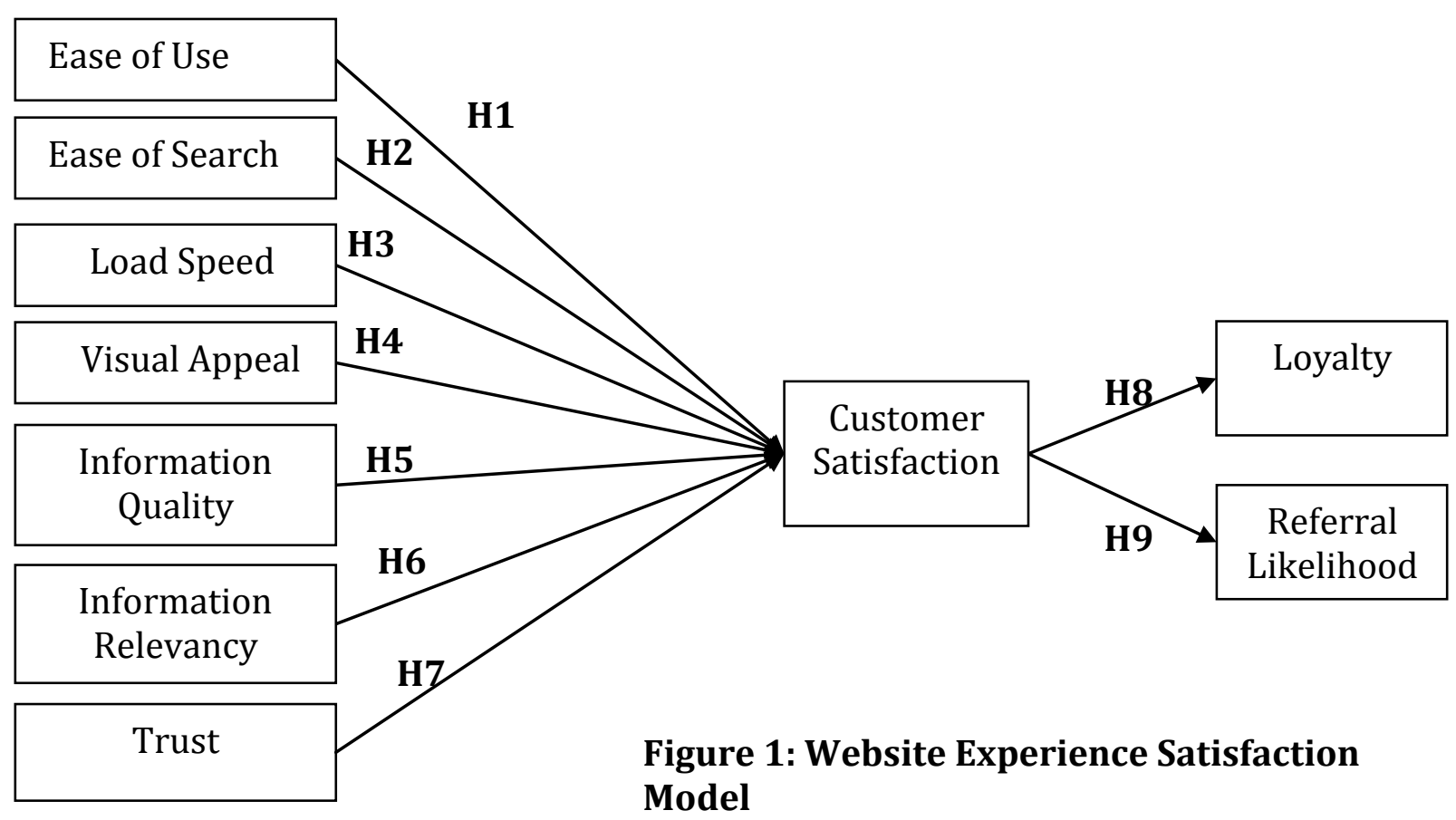




\section{PARTICIPANTS AND DESIGN}

One hundred and sixty-eight post graduate and undergraduate business school students were recruited to participate in the survey. A \$100 gift certificate was offered as an incentive to participate. The survey was conducted online. Participants were instructed to think of a product they were planning to purchase in the near future. They were then instructed to find a website where they could purchase the product, add the product to their shopping basket, and progress through the checkout process as far as they could until they were required to provide payment details. Participants at this stage could either follow through with their purchase, or abandon their cart. They were then asked to complete the questionnaire consisting of the model variable questions (table 1). All variables were measured on seven point Likert Scales.

TABLE 1

Model Variable Measures

Variable Name Variable Measurement

Ease of Use

Ease of Search

Information Quality

Information Relevancy

Satisfaction

Likelihood of referral

Loyalty

Trust

Load Speed

Visual Appeal
How easy was it to find your way around?

How easy was it to search for information?

How was the quality of information?

How relevant was the content?

How satisfied are you with your experience?

Would you refer others to this website?

Would you visit this website again?

Do you trust this website?

How fast do the pages load on this website?

How attractive is this website? 


\section{RESULTS}

The estimation converged to an admissible solution, yielding a good fit of data to the model $\chi^{2}(89)=246.53(p<.001)$; NFI $=.78 ; \mathrm{RFI}=.70 ; \mathrm{CFI}=.84 ;$ RMSEA $=$ .10

The structural equation model above gives you some indication of how much impact each dimension in general has on satisfaction, and how strongly website experience satisfaction affects loyalty and likelihood of referral. The standardized regression weights in the Webreep Structural Equation Model on the left suggest that Trust (.53) and Content Quality (.42) have the strongest impact on Satisfaction, followed by Performance (.31) and Navigation (.16). The model shows that website experience Satisfaction has extremely strong effects on Likelihood of Referral (.77) and Loyalty (.80). The model shows that $87 \%$ of the variance of website experience satisfaction can be explained by the six factors identified. This is statistically high suggesting the conceptualized factors explain customer satisfaction well.
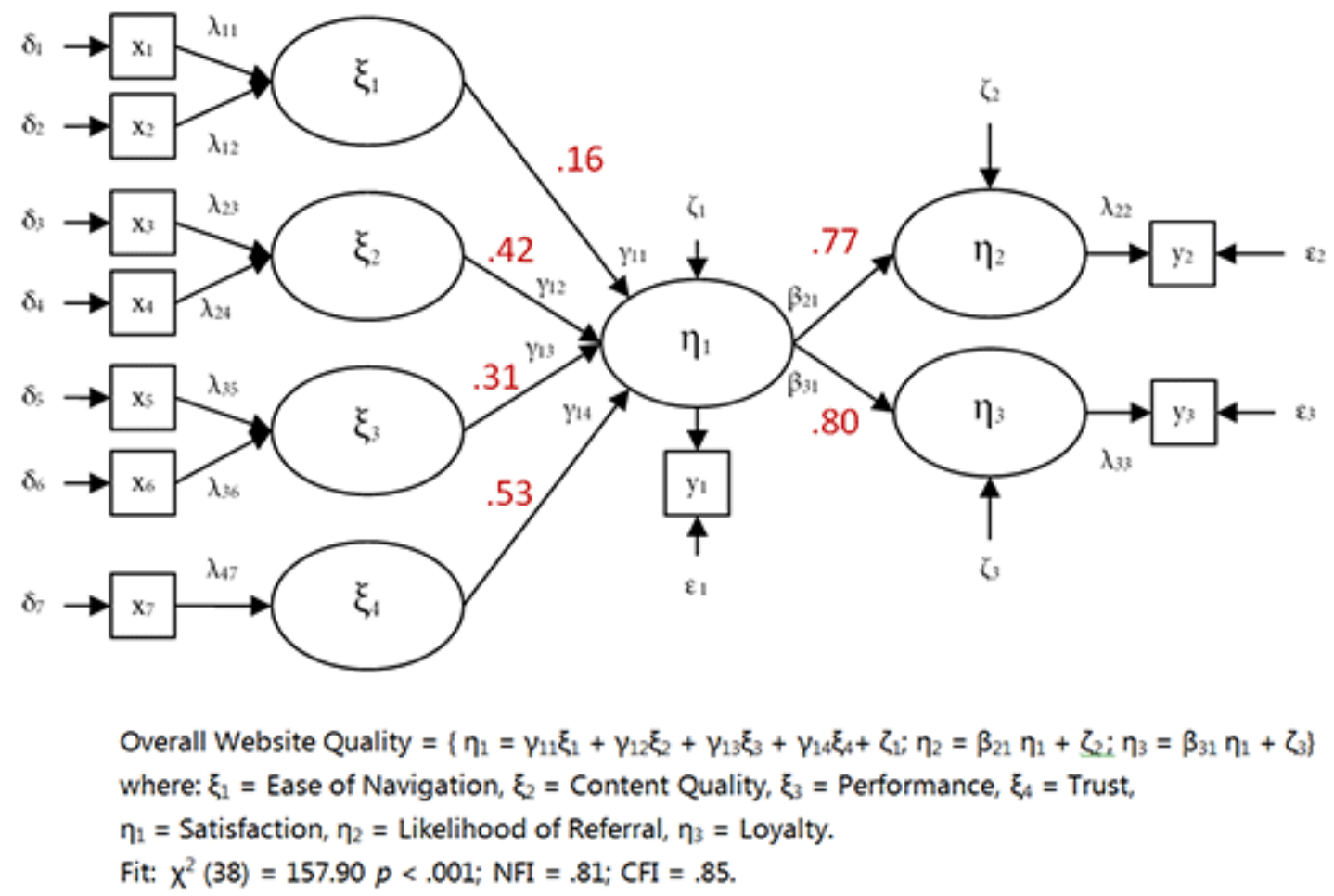

\section{DISCUSSION}

This research sought to develop and test a parsimonious model to capture website experience quality by measuring satisfaction, likelihood of referral, and loyalty. Specifically, the aim was to develop an instrument to capture the variance of each construct in the model that was brief enough to have practical usage as on online customer satisfaction feedback form. The result of our efforts is a ten item instrument with tight psychometric properties that captures significant proportions of website satisfaction variance. Since the instrument is only ten items, it can be practically deployed on a website as a quick measure of website visitor satisfaction. 


\section{REFERENCES}

Alba, J. W., Lynch, J., Weitz, B., Janiszewski, C., Lutz, R., Sawyer, A. \& Wood, S. (1997) Interactive home shopping: Consumer, retailer, and manufacturer incentives to participate in electronic marketplaces. Journal of Marketing, 61, 38-53.

Anderson, E. W. (1998) Customer Satisfaction and Word of Mouth. Journal of Service Research, 1, 5-17.

Anderson, E. W. \& Sullivan, M. W. (1993) The Antecedents and Consequences of Customer Satisfaction for Firms. Marketing Science, 12, 125-143.

Ba, S. \& Pavlou, P. A. (2002) Evidence of the effect of trust in electronic markets: Price premiums and buyer behavior. MIS Quarterly, 23, 243-268.

Balasubramanian, S., Konana, P. \& Menon, N. M. (2003) Customer Satisfaction in Virtual Environments: A Study of Online Investing. Management Science, 49, 871-889.

Barnes, S. J. \& Vidgen, R. (2001) An evaluation of cyber-bookshops: The webqual method. International Journal of Electronic Commerce, 6, 11-30.

Dick, A. S. (1994) Customer Loyalty: Toward an Integrated Conceptual Framework. Journal of the Academy of Marketing Science, 22, 99-113.

Forrester (2009) Forrester Research Web-Influenced Retail Sales Forecast. Forrester Research Inc.

Gefen, D., Karahanna, E. \& Straub, D. W. (2003) Trust and TAM in online shopping: An integrated model. MIS Quarterly, 27, 51-90.

Gruen, T. W., Osmonbekov, T. \& Czaplewskia, A. J. (2006) eWOM: The impact of customer-to-customer online know-how exchange on customer value and loyalty. Journal of Business Research, 59, 449-456.

Loiacono, E. T., Watson, R. T. \& Goodhue, D. L. (2007) WebQual, An Instrument for Consumer Evaluation of Websites. International Journal of Electronic Commerce, 11, 51-87.

Ramsay, J., Barbesi, A. \& Preece, J. (1998) A psychological investigation of long retrieval times on the World Wide Web. Interacting with Computers, 10, 77-86.

Ranganathan, C. \& Ganapathy, S. (2002) Key dimensions of business-to-consumer web sites. Information \& Management, 39, 457-465

Reichheld, F. F. \& Schefter, P. (2000) E-loyalty. Harvard business review, 78, 105.

Shankar, V., Smith, A. K. \& Rangaswamy, A. (2003) Customer satisfaction and loyalty in online and offline environments. International Journal of Research in Marketing, 20, $153-175$

Teo, T. S. H. \& Yeong, Y. D. (2003) Assessing the consumer decision process in the digital marketplace. Omega, 31, 349-363.

U. S. Census Bureau (2010) Quarterly retail e-commerce sales: 3rd quarter 2010. U S Department of Commerce. 
218 Coker, $B$.

Yoo, B. \& Donthu, N. (2001) Developing a Scale to Measure the Perceive Quality of An Internet Shopping Site (SITEQUAL). Quarterly Journal of Electronic Commerce, 2, $31-47$. 